Volume 12 | Issue 3

September 2021

\title{
"I Used to be Scared to Even Like Stand Beside Somebody Who Had It": HIV Risk Behaviours and Perceptions Among Indigenous People Who Use Drugs
}

Jennifer Lavalley

University of British Columbia, Canada, jennifer.lavalley@bccsu.ubc.ca

Western Aboriginal Harm Reduction Society

Canada,wahrsdtes@gmail.com

Christopher Livingstone

Western Aboriginal Harm Reduction Society, Canada, livingstonechris@yahoo.com

Melissa Steinhauer

Western Aboriginal Harm Reduction Society, Canada, steinhauer.melissa07@gmail.com

Ashley Goodman

University of British Columbia, Canada, ashleynicolegoodman@gmail.com

Thomas Kerr

University of British Columbia, Canada, bccsu-tk@bccsu.ubc.ca

Recommended Citation

Lavalley, J., Western Aboriginal Harm Reduction Society, Livingstone, C., Steinhauer, M., Goodman, A., \& Kerr, T. (2021). “I used to be scared to even like stand beside somebody who had it": HIV risk behaviours and perceptions among Indigenous people who use drugs. The International Indigenous Policy Journal, 12(3). https://doi.org/10.18584/iipj.2021.12.3.10878 


\title{
"I Used to be Scared to Even Like Stand Beside Somebody Who Had It": HIV Risk Behaviours and Perceptions Among Indigenous People Who Use Drugs
}

\begin{abstract}
Objectives: In Canada, and elsewhere, Indigenous people who use illicit drugs and/or alcohol (WUID/A) experience a disproportionate burden of HIV-related harm. This study examined HIV risk perceptions and behaviours among Indigenous people WUID/A living in the Downtown Eastside (DTES) and the policies and practices that shape inequities and vulnerabilities for them in HIV testing and treatment. Further, we aimed to situate the vulnerabilities of Indigenous people WUID/A in HIV care within the context of wider structural inequality and generate recommendations for culturally relevant and safe HIV treatment options.
\end{abstract}

Methods: This research employed an Indigenous-led community-based participatory approach using talking circles to explore experiences of Indigenous people living with HIV. Under the participatory research framework, community researchers led the study design, data collection, and analysis. Talking circles elicited participants' experiences of HIV knowledge, testing, and treatment, and were audio-recorded and transcribed. Data were coded line-by-line and codes were organized into themes.

Results: Five key themes were identified via the talking circles: evolving HIV risk perceptions (e.g., HIV knowledge and testing, and "intentional exposure"); research as an avenue for HIV testing; HIV treatment and discussions about grief and loss; HIV-related stigma and discrimination; and the importance of culturally-relevant and safe HIV treatment options for Indigenous people WUID/A.

Discussion: Our work reveals that Indigenous people WUID/A do not have adequate access to HIV knowledge and education, often limiting their ability to access HIV testing and supports. Participant stories revealed both internalized and community stigma and discrimination, which at times compromised connection with participants' home communities. Further, our findings point to a failure in the public health system to deliver accessible HIV information to Indigenous Peoples, hence, many participants have solely relied on participation in communitybased research studies in the Downtown Eastside (DTES) for HIV education and knowledge. There is an urgent need for accessible, culturally safe, and community-based education and treatment options for Indigenous people WUID/A within HIV care.

\section{Keywords}

Indigenous Peoples, substance use, community-based participatory research, Indigenous methodologies, marginalized populations, HIV/ Aids, HIV treatment

Creative Commons License (c) ${ }_{\mathrm{BY}} \mathrm{No} \mathrm{NO}$

This work is licensed under a Creative Commons Attribution-Noncommercial-No Derivative Works 4.0 License. 


\section{"I Used to be Scared to Even Like Stand Beside Somebody Who Had It": HIV Risk Behaviours and Perceptions Among Indigenous People Who Use Drugs}

Across the globe, HIV-related health disparities and stigma among those living with or vulnerable to HIV infection, especially those who are also structurally vulnerable and marginalized, have been widely documented (Goldenberg et al., 2017; Goodyear \& Cusick, 2007; Hatzenbuehler et al., 2011; Liamputtong, 2013; Shannon et al., 2008). Among those most affected by these HIV-related disparities and harms are Indigenous Peoples (Barker et al., 2019; Center for Disease Control and Prevention, 2017). These disparities and harms include, but are not limited to, higher mortality rates, lack of access to health services, and multi-layered experiences of stigma and discrimination (Woodgate et al., 2017). There are inextricable links between the social, economic, cultural, and political conditions_-including racism and colonization - faced by Indigenous Peoples and the risk of HIV infection (Negin et al., 2015). Moreover, the everyday realities of Indigenous Peoples have not been adequately included in the global HIV response (HIV/AIDS and Indigenous Peoples, 2009; Ontario HIV Treatment Network, 2019).

In Canada, it is well recognized that Indigenous Peoples (First Nations, Inuit, and Métis) have inequitable access to healthcare, are overrepresented in the HIV epidemic, and experience a disproportionate burden of HIV-related harms (Barker et al., 2019; Negin et al., 2015; Woodgate et al., 2017). For example, although Indigenous people make up $4.9 \%$ of the total population in Canada (Statistics Canada, 2018), they account for approximately $11.3 \%$ of new HIV infections (Public Health Service Canada, 2018). Additionally, a small but growing body of evidence suggests that conventional approaches to HIV care, support, and treatment do not meet the unique cultural needs of Indigenous people living with HIV, contributing to poor health outcomes among this population (Jackson \& Reimer, 2008; McCall \& Lauridsen-Hoegh, 2014). Furthermore, past research has shown that Indigenous people who use illicit drugs and/or alcohol (WUID/A) face compounded stigma and discrimination in healthcare settings, which in turn leads to poorer access and care (Goodman et. al., 2017), including treatment and care for substance use and HIV disease. By consequence, Indigenous people WUID/A often live with health challenges that go untreated, resulting in much preventable suffering, as well as a reluctance to seek care in the future.

While these studies importantly elucidate some of the reasons why conventional HIV care does not meet the needs of Indigenous Peoples, they do not focus exclusively on the unique experiences of Indigenous people WUID/A. Past research has shown that Indigenous people WUID/A face compounded stigma in healthcare settings leading to poorer access and care (Goodman et al., 2017). Drawing on a structural approach, we therefore examine and centre risk perceptions and behaviours among Indigenous people WUID/A.

The need to understand the perceptions of Indigenous people WUID/A is particularly important in Vancouver, Canada's major western urban centre-home to the largest urban Indigenous population in British Columbia (BC; McCall \& Lauridsen-Hoegh, 2014), most acutely visible in Vancouver's Downtown Eastside (DTES; Statistics Canada, 2015). The DTES is a low-income neighbourhood that is a site of Canada's largest street-based illicit drug scene, characterized by high rates of poverty, substance use, violence, homelessness, and, historically, the epidemic of HIV infection (BC Coroners Service, 2020; Hyshka et al., 2012; Werb et al., 2010; Wood \& Kerr, 2006). Despite ongoing research 
efforts to understand the health inequities experienced by Indigenous Peoples, little is known about the distinct experiences of Indigenous people WUID/A in the context of accessing HIV testing and treatment and experiences of stigma and discrimination within their home communities. Given the ongoing challenges related to HIV among Indigenous Peoples in Canada, we aim to make room in academia for the prioritization of the voices of Indigenous people WUID/A in order to bring greater attention to cultural factors in HIV-related education, treatment, and care.

\section{Current Project}

This research was undertaken in Vancouver, BC, where there are approximately 14,000 Indigenous people, who account for $2.2 \%$ of the population (City of Vancouver, 2017). All participants involved in this research consisted of community members who identify as Indigenous people WUID/A living in the inner-city neighbourhood of Vancouver's Downtown Eastside (DTES) with some also identifying as a person living with HIV. The DTES is characterized by high rates of poverty, homelessness, substance use, mental health issues, and violence, along with immense social and economic marginalization (Kazempiur \& Halli, 2000; Miller et al., 2002; Shannon et al., 2008; Spittal et al., 2002; Werb et al., 2010; Wood \& Kerr, 2006). The DTES is also home to at least one-third of the city's total Indigenous population (Cardinal \& Adin, 2005) and well known for its “open” drug scene (City of Vancouver, 2013).

\section{Conceptual Framework}

The research team for this project includes the Western Aboriginal Harm Reduction Society (WAHRS), and academic researchers from the British Columbia Center on Substance Use (BCCSU), as well as an Indigenous research coordinator. According to O’Brien et al. (2020), the leadership of Indigenous researchers necessitates culturally appropriate research and ensures the overall appropriateness, relevance, and success of a research project. Under the umbrella of Vancouver Area Network of Drug Users (VANDU), WAHRS is an Indigenous-led organization representing current or previous users of illicit drugs and or illicit alcohol. The organization is dedicated to harm reduction and improving the quality of life of other Indigenous people WUID/A. Their work involves the development of support, education, and training programs that reflect the values of Indigenous Peoples. Within the context of this project, WAHRS board members collaborated at all stages in the research design (e.g., research methodology, topic of interest, data collection and analysis, etc.) and are both community researchers and participants.

The BCCSU provided academic and research support and has a long-standing research relationship with the DTES community. The BCCSU partnered with WAHRS to conduct community-based research to explore their experiences with HIV. Following the principles of community-based participatory research and Indigenous methodologies, this project incorporates the values and beliefs of Indigenous people WUID/A in its design, methods, and analysis (Lavallée, 2009; Smith, 2013; Tuck, 2009), ensuring that the expertise, knowledge, and experiences of Indigenous people WUID/A were leveraged and respected (O'Brien et al., 2002). For this project, WAHRS board members had active roles as community researchers, and employed Indigenous ways of knowing and sharing throughout the project. Talking circles were used to explore and share personal experiences with HIV amongst peers. 
This article is designed to illuminate the distinct experiences and perceptions of Indigenous people WUID/A vulnerable to HIV.

\section{Methods}

\section{Eligibility and Recruitment}

The methods used in this study have been described in detail in Goodman et al. (2017) and Goodman et al. (2018). A series of peer-facilitated talking circles were held to explore Indigenous community members' experiences with HIV. Talking circles are a culturally appropriate research method grounded in Indigenous knowledge and reflect the values and beliefs of Indigenous communities (Lavallée, 2009; Smith, 2013). Talking circles were facilitated by two WAHRS board members (community researchers) and participation was open to the WAHRS membership. Individuals participated in one talking circle each. In total, 31 Indigenous people WUID/A participated in the talking circles. Talking circle participants were recruited using convenience sampling during the community organization's weekly membership meetings through a draw-system, which was used to select a maximum of 10 participants for each talking circle. WAHRS board members contributed their own lived experiences during the talking circles. In total, three talking circles were completed, averaging 1 hour in length. Ethical approval was granted by the University of British Columbia Providence Healthcare Research Ethics Board.

\section{Data Collection}

During each talking circle, the research topic was introduced to the group by the facilitators, who then initiated the talking circle by sharing their personal experiences with HIV. An eagle feather, a cultural symbol signifying honour and respect, was chosen and used to guide the facilitation. If desired, participants were allowed to pass on speaking. Talking circles were audio recorded, transcribed verbatim, and reviewed for accuracy and preliminary themes by the community researchers and research coordinator.

\section{Data Analysis}

WAHRS board members participated in the research as community researchers. Qualitative analysis of the data was undertaken individually and as a group. First, we conducted a detailed review of the transcripts. Preliminary themes and descriptive quotes emerged and were presented to the WAHRS Board for review. Each transcript was read aloud by the research team and then coded line-by-line by hand to identify key themes and recommendations. WAHRS presented a summary of the analysis and findings to a large membership meeting attended by 35 members. Members were encouraged to provide insight on the research topic and findings, as well as to contribute to the recommendations.

Data was broadly reviewed by an Indigenous researcher from the BCCSU for the purpose of drafting an academic peer-reviewed research article. Numerous joint meetings were held with WAHRS board members to share, discuss, and revise the manuscript. Manuscript meetings were audio recorded and transcribed verbatim by the first author. The first author reviewed the transcripts to ensure the community researchers' voices were accurately represented in the writing of this article. 


\section{Findings}

The data derived from the talking circles elucidated considerable misinformation about HIV and a lack of culturally safe and accessible HIV-related education. Leading themes that emerged from participant narratives included evolving HIV risk perceptions (e.g., HIV knowledge and testing, and "intentional exposure"), research as an avenue for HIV testing, changing experiences with HIV treatment, HIVrelated stigma and discrimination, and culturally safe and community-based HIV education. Participants also emphasized their experiences of grief and loss, HIV-related stigma and discrimination, and the importance of accessible and culturally safe treatment options. Participants all self-identified as Indigenous $(n=31)$ and cisgender: $\operatorname{men}(n=18)$, women $(n=13)$.

\section{Evolving HIV Risk Perceptions}

\section{The DTES and Evolving HIV-Related Knowledge}

Several participants' narratives reflected common misconceptions about HIV and people living with HIV. However, a noticeable feature of participants' life stories was the changing knowledge and perceptions of HIV after moving to Vancouver-particularly after moving to the DTES. In general, most participants spoke about their initial lack of knowledge and information about HIV and how it is transmitted. For example, a female participant explained her early perceptions of HIV transmission:

But yeah it was kind of a shocker to me what HIV was, as it was kinda like um, like oh my god you know, don't touch a person or, even breathe in the same air. (Female participant \#1, Talking Circle \#3)

Two other participants shared related misconceptions about "catching" HIV, which led some to believe they were not at risk for acquiring HIV. First, a male participant talked about his initial perception of how HIV was contracted:

And uh, when I first heard of HIV like they said you can get it from uh a lion or a, a monkey. That's where it came from. The jungles. And I used to think about that, if that's true. And uh, everybody kept saying yeah you can catch it from monkeys. (Male participant \#1, Talking Circle \#3)

Second, a participant noted that she used to think she could contract HIV by touching someone with the virus:

When I first came to Vancouver ... I used to be scared to even like, stand beside somebody who had it. 'Cause, they said, contract the, [inaudible] contract like, like through the air by touching anybody. [It has] to be like through sex and stuff like that. I understand-Like I, read a lot about that. (Female participant \#2, Talking Circle \#3)

Another participant explained how when she first moved to Vancouver, HIV transmission was primarily seen as a "man-to-man thing." 
My experience with HIV was, years ago when I first came to the street here, like near the beginning, when the people started getting it, and blamed it on like man-to-man type thing. And it was a very, you know, they weren't telling much people about what it was and stuff like that. (Female participant \#4, Talking Circle \#2)

Despite originally having limited knowledge about HIV, several participants talked about their evolving understanding of HIV transmission and people living with HIV after moving to the DTES. For many of the participants their perception of HIV changed over a period of time and several participants talked about how their personal stereotypes and stigma toward people living with HIV shifted throughout their lifetime:

Anyways, I used to be scared to get this 'cause at the time, I thought the only way to contact HIV was only through sex okay. Now I know different. It's important that we uh, we tell people about other ways to get uh HIV'cause at the time I never knew. (Female participant \#1, Talking Circle \#1)

\section{Risk Behaviour and HIV Testing}

HIV risk perceptions varied among participants. Although many of the participants perceived themselves to be low risk for contracting HIV, some went on to describe themselves as "lucky" given their ongoing engagement in high-risk behaviours. Further, many of those who engaged in ongoing risk behaviour resorted to frequent testing in response. For example, a male participant explained he was lucky given his "risky behaviours" (e.g., drug use):

I've been lucky so far that, it hasn't happened to me [contracting HIV]. Um, I've been blessed not to, have gotten it. Uh, even though, through the risky behaviours of, [inaudible] there on, drugs or whatever. (Male participant \#1, Talking Circle \#1)

Another participant expressed similar feelings about being "lucky" despite being a person who injects drugs:

But uh yeah I been pretty lucky I haven't caught it [HIV] because I'm uh, oh I inject. And uh, and I, and I get, and I get checked out every three months so. (Male participant \#3, Talking Circle \#1)

A female participant explained that she feels "lucky" that she has not contracted the virus because she has shared needles with a person with HIV:

You know some of the people that I shared uh needles with, some of them has uh are not around. They contracted HIV and they're gone right. That's why I'm so lucky to be here. I don't have nothing. (Female participant \#3, Talking Circle \#3)

Higher perceived risk of HIV transmission was often associated with sexual risk behaviours and for some prompted regular HIV testing. Although participants were well aware of the risks, some persisted in engaging in riskier behaviours, but also went for HIV testing frequently. This was the case for one participant who regularly practices unsafe sex: 
You know what, you might think I'm crazy but I still have practised unsafe sex eh. Because I'm not that type of person who will use it [safe sex supplies]. And um, I don't know if I'm playing with fire, but I get tested every four months, and I'm always negative. (Male participant \#6, Talking Circle \#1)

\section{Intentional Exposure}

Interestingly, two participants described incidents of "intentional exposure" to the HIV virus. First, the above participant explained that he tried to "get HIV" so he could be eligible for Disability Assistancegovernment financial assistance for those living with a disability:

You know. Like I tried my hardest to get HIV for 2 years. And I didn't get it. You know I kept going getting tested. (Male participant \#6, Talking Circle \#1)

A male participant discussed a similar dynamic with a former roommate:

And he ended up acquiring it, quite frankly because the church that he was part of, looked down upon homosexuality. It wasn't allowed. You're not allowed to have a partner. So he actually [inaudible] went out to the go get, HIV. Like unsafe stuff uh, known sexual meeting places for anonymous sex. He would frequent those so that he could catch it 'cause he hated himself so much. Which was-That's how he explained it to me. (Male Participant \#5, Talking Circle \#1)

\section{Research as an Avenue for HIV Testing}

Several participants discussed how involvement with research studies in the DTES was a central avenue for HIV testing and, for some, these research studies have become both a source of supplemental income (i.e., via participant honoraria) and an ongoing source of routine testing. Five participants routinely accessed an ongoing local cohort study as a first point of contact for HIV testing. A male participant stated:

I heard about HIV but, not that much. And uh, but then after that I start to get like-I didn't want to get it [HIV] so, tested like twice a year, like at [clinic name]. (Male participant \#2, Talking Circle \#1)

Ongoing involvement with research studies then became a place where participants could access yearly HIV testing:

I go to [name of clinic] every 6 months for blood tests. And, if um, they don't get a hold of you in a couple weeks that means you're uh okay I guess. (Female participant \#4, Talking Circle 3)

General HIV knowledge and access to HIV testing was sometimes associated with research incentives in the DTES. By engaging those living in the DTES with research incentives, residents' engagement and linkage to HIV testing improved. A participant explained that moving to the DTES exposed her to a lot of "firsts" - including HIV testing:

My first HIV testing was here in the Downtown Eastside when they did the "blowout." You get the 5-dollar Army \& Navy. (Female participant \#1, Talking Circle 2) 
Similarly, another participant, who identified as a sex worker, explained that she did not know much about HIV until she accessed services from a van ran by those leading a research study on sex work. She stated:

Yeah I didn't know too much about HIV either but uh, because of the line of work I am in-I work on the streets right but anyways, I've known a couple girls that have HIV. And um because I just started hanging around down here and um, hanging around the corner and then a van pulled up ... so they said oh here, we'll give you a card, you go, test yourself. (Female participant \#2, Talking Circle \#1)

Here she explains that this research incentive has led to other "girls" [sex workers] receiving regular HIV treatment:

They [research staff] drive around maybe once or twice a week and they hand out tickets for the girls to come in and get themselves checked out. Which is a good way of doing it because if you didn't have that incentive, they wouldn't do it. (Female participant \#2, Talking Circle \#1)

\section{HIV Treatment and Discussions About Grief and Loss}

Participants discussed three major themes related to experiences with HIV treatment. First, they talked about resistance to engaging with HIV treatment (e.g., taking medication). Subsequently, stories of grief and loss were prevalent in their stories. The success stories of those taking medication, in more recent years, also emerged as a major theme in their narratives.

\section{Experiences with HIV Treatment}

Many participants commented on experiences they have had with a friend or family member living with HIV who had chosen not to take medication. A female participant said, "when I moved down here I found out my friend of mine, had HIV and she wasn't taking her medication” (Female participant \#3, Talking Circle \#1). Another participant discussed how her family member agreed to take treatment only after they got "too sick":

I have a family member that's HIV. And I've kept after her to get the treatments right. 'Cause there is treatment ... I know it doesn't cure it completely but you can uh, get these treatments. I kept after her. No way she wouldn't do it. Until she really, really got too sick. So that's when she decided to take the treatment. So, I think it's important that we uh, tell our members about. (Female participant \#1, Talking Circle \#1)

Participants also described experiences of their loved ones "surviving" for long periods of time without receiving treatment:

I have had friends that have had HIV for a long time-20 years. Maybe more than 20 years ... they still live. I don't see why you know. They survived, but they don't take medication. (Male participant \#4, Talking Circle \#1) 
Participants also commonly expressed that they witnessed loved ones die due to avoiding treatment and medication:

That was sad to watch him. You know. Didn't really know about HIV/AIDS. Or heroin before I came to Vancouver. Everybody's on heroin or whatever right. Or methadone so. Just kinda sad to watch somebody that you did know in their last stage of HIV, and dying 'cause they just want it. (Female participant \#5, Talking Circle \#3)

Participants also shared more recent stories of treatment success - in that either themselves or loved ones were successful in maintaining HIV treatment. A male participant described his past roommate's experiences with HIV treatment:

Thing is though, that I'm impressed with is, whatever happened, his count went down enoughI mean, when I was his roommate, that was like in 1992. And now we're talking 2013 and he's still alive and well. You know. And doing really "good." I mean he looks fantastic. (Male participant \#5, Talking Circle \#1)

Here, a male participant described his journey in becoming "undetectable" — when the viral load of a person living with HIV cannot be detected by a blood test:

Ten years ago, I had full blown AIDS. They said I had 4 weeks to live. Now, I'm undetectable. They gave me experimental drugs. Like I was a guinea pig. That fucking near killed me ... But it cured me of AIDS. I'm still alive. And I'm undetectable now. Which doesn't mean much. Just AIDS is gone that's all. (Male participant \#2, Talking \#2)

\section{Grief and Loss}

HIV-related grief and loss was an overwhelming theme in participants' narratives. Participants who witnessed a loved one experiencing health decline or passing often mentioned that their loved one was not taking their medication. Many participants had experiences of knowing a friend or family member dealing with HIV-related complications. A male participant reported:

My last friend, she was a woman eh. And so she died of AIDS man. She went from 160 pounds to 120 pounds, 90 pounds and that was it for her. (Male participant \#4, Talking Circle \#1)

Another noted:

But I know people who've had it and, I've lost a lot of friends. Lots of friends over the years from it [HIV]. (Male participant \#1, Talking Circle \#1)

The emotional context facing family members supporting loved ones was profound. A female participant shared her story of witnessing the declining health of her nephew and sister:

And, not only that like, my nephew, my sister's stepson he's in the hospital. He's dying of HIV. He was in St. Paul's. We didn't know for a long time where he was and finally found out. I'm scared, like I am scared to go visit him ... 'cause like he's lost a lot of weight and then, for my sister like, I don't know. It is very hard like you know, for people that have sickness and then I've 
known like a lot of people that have HIV are my friends. (Female participant \#2, Talking Circle \#3)

\section{HIV-Related Stigma and Discrimination}

Stigma and discrimination caused significant barriers to support for Indigenous people living with HIV. Participants spoke about receiving limited support from peers, family, and community, as well as isolation and social rejection, after being identified as a person living with HIV. Some participants shared their personal stories of fearing or experiencing rejection from people in their social networks. The following participant shared his experience of being rejected by his family when he was diagnosed with HIV:

I miss my hugs from my kids when it-I had the HIV. They found out. No more hugs. No more jumping up [for] me and my kids. Go to my family's, I got my own cups, spoons stuff like this put away eh. It's their house [inaudible] go by their rules. ... So uneducated. (Male participant \#4, Talking Circle \#2)

Internalized HIV-related stigma and discrimination prevented some participants from disclosing their HIV status to their families:

And, none of my brothers, sister know, that I, got HIV. And none of my families, three families, know that I got HIV. 'Cause I never talk to 'em, since I found out 15 years ago I, kept it to myself. I just thought I was gonna die and, now I’m okay about it. (Female participant \#4, Talking Circle \#2)

Participants also encountered stigma and discrimination on a broader community level. One participant talked about his fear of "banishment" from his home First Nations community and family due to his HIV status:

And um, people's frame of mind back then was that um, and um my fear was to get banished from my reservation eh. Or even my number one fear was getting banished from my family. (Male participant \#6, Talking Circle \#1)

Another participant expressed a comparable experience with stigma and blame in his home community.

Once it [HIV] got into the reserves ... it did spread. And a lot of finger-pointing and, blaming and, uh anybody who came from, somewhere else, was likely the most — was a likely suspect who brought it in. (Male participant \#1, Talking Circle \#1)

\section{Culturally Safe and Community-Based HIV Education}

Participant's commonly positioned HIV education as inaccessible to residents of the DTES and offered criticisms and insights about the delivery of HIV-related information and services. A female participant noted that while health educators provide HIV education to community organizations, there is a lack of education for those who do not regularly access these organizations-namely for "people on the street": 
Education is really needed down here [DTES]. You know 'cause, I walk the streets up here and you know, they're talking about AIDS and HIV, and it's just such bad stuff that they're saying. You know like. No education. You know I think we need to start educating the people on the street. Not just the people come into our organizations [Vancouver Area Network of Drug Users], that's all we know. But there's people who don't come to these places. ... People that need to be educated, so you know that stigma's not out there and that hatred. (Female participant \#1, Talking Circle \#2)

She also noted the ways in which HIV education can be more accessible to those living in the DTES:

When people don't know the ignorance of people, who don't know about HIV, it needs to be told, maybe in a safe, clean way. You know like, it doesn't have to be you know "mumbo jumbo" ... just something plain and simple. That it can be told to the people on the streets. In our kind of language. In the, you know, the street language of the "Downtown Eastside language." (Female participant \#1, Talking Circle \#2)

Further, some participants talked about the importance of delivering information in an accessible and culturally safe way for Indigenous Peoples. One woman shared her idea of an accessible Indigenousspecific cultural resource:

I mean I wish they would find a way to, bring us information that we can enjoy reading. You know maybe pictures, cartoons. I dunno. Something that we can, that catches our eye. That, um maybe, cultural. In a cultural way maybe, if we could get something for, Aboriginal people to read. (Female participant \#1, Talking Circle \#4)

She also noted that accessible HIV-related information should be "something easier for us to access, knowledge and current knowledge ... 'Cause things change. Things change. With treatment." Further, as a female participant nicely summarizes, "The more you know, the more better, better off you are" (Female participant \#3, Talking Circle \#2).

\section{Discussion}

The knowledge and experiences of Indigenous people WUID/A living in the DTES of Vancouver, BC, provide valuable insights regarding everyday HIV risk behaviours and HIV-related perceptions. The intersecting issues affecting many of the Indigenous people in this study, including discrimination, marginalization, and substance use, are the result of the legacy of racism and colonialism in Canada. These intersecting issues also contribute to disparities in HIV knowledge, prevention, and support, which not only impact access to HIV knowledge and testing, but also limit engagement with and access to HIV treatment and care. Some participants also experienced HIV-related stigma and discrimination within their own First Nations communities, as well as profound experiences of trauma related to grief and loss. At the same time, while our findings further demonstrate that Indigenous people WUID/A have gained better access to HIV testing and supports, enhanced access to culturally safe and community-based education and treatment options still needs to be prioritized.

In order to investigate the experiences of Indigenous people WUID/A, who are vulnerable to HIV, we must first understand the ongoing systemic impacts of colonization on Indigenous Peoples' health. 
Previous research on this impact has revealed that colonization continues to shape Indigenous lives and health in complex ways, and this remains true for experiences with HIV prevention and treatment (Allan \& Smylie, 2015; Loppie Reading \& Wien, 2013). Subsequently, the impacts of colonization are integral to discussions surrounding Indigenous Peoples' experiences and, in this case, are central to the discussion surrounding Indigenous people WUID/A and HIV. Without this understanding and articulation, Indigenous Peoples' experiences of structural violence, racism, and social and health inequities are reinforced (Adelson, 2004).

Health inequities experienced by Indigenous Peoples (e.g., inadequate access to healthcare services, higher morbidity and mortality rates, etc.) are linked to the intergenerational and continuing impacts of colonization, including the residential school experience, overrepresentation in the child welfare system, ongoing colonial policies (i.e., the Indian Act), and the Sixties Scoop (Allan \& Smylie, 2015; Goodman et al., 2017; HIV/AIDS and Indigenous Peoples, 2009; Loppie Reading \& Wien, 2013; Negin et al., 2015). Prior studies have shown how experiences with colonial trauma can shape HIV risk among Indigenous Peoples (Bingham et al., 2014; Negin et al., 2015). For example, a study looking at the HIV infection risk among Indigenous women engaged in street-based sex work found that intergenerational trauma was a contributing factor (Bingham et al., 2014). Research has linked poorer health outcomes among Indigenous people, particularly those living with HIV, compared to non-Indigenous groups, with poor health most often stemming from the impacts of marginalization, colonization, and ongoing colonial practices that perpetuate state violence (Barker et al., 2019; HIV/AIDS and Indigenous Peoples, 2009; Negin et al., 2015; Woodgate et al., 2017).

Our findings importantly highlighted that Indigenous people WUID/A in Vancouver do experience disparities in access to HIV prevention (i.e., education and testing), uptake of HIV care, and treatment outcomes. However, changes in HIV-related knowledge were associated with improvements in HIV treatment access and treatment acceptance. This finding is consistent with previous research that has linked increases in HIV knowledge to reductions in HIV risk behaviours (De Santis et al. , 2017). For Indigenous Peoples, the lack of engagement with HIV treatment (i.e., taking medication) has been recognized as a common experience (Barker et al., 2019; Milloy et al., 2016). Participants revealed that insufficient knowledge about HIV may discourage people from accessing appropriate HIV testing. Similarly, previous research reported low levels of knowledge about HIV among Indigenous youth and their parents, often leading to reduced prevention and testing (Fagan \& McDonell, 2010; Mitchell et al., 2004; Negin et al., 2015).

However, we also found that, in recent years, there has been significant improvement in HIV knowledge, as well as the uptake of HIV testing and treatment among Indigenous people WUID/A (Barker et al., 2019). While many participants described their loved ones "falling ill" from HIV, recent accounts of success stories affirm epidemiological evidence suggesting improved uptake of HIV testing and medication access among Indigenous people WUID/A (Martin et al., 2011; Milloy et al., 2016; Montaner et al., 2014; Negin et al., 2015). We also attribute this finding to the fact that the DTES was the centre of a massive epidemic, leading to considerable HIV testing services being put in place, and the raising HIV awareness among residents. This finding further demonstrates that healthcare systems have denied equitable access to life-saving information to Indigenous communities. 
The positive impact of access and adherence to antiretroviral therapy (ART) on rates of morbidity and mortality among people living with HIV has been well established (Martin et al., 2011; Milloy et al., 2016; Montaner et al., 2014; Negin et al., 2015). However, marginalized people living with HIV, including Indigenous Peoples, face significant barriers in accessing these treatments (Barker et al., 2019). Our findings further demonstrate that tailored interventions can improve the health and wellbeing for those who face intersecting barriers to HIV treatment, such as racism, substance use, sexism, transphobia, etc. (De Santis et al., 2017; Price et al., 2018; Wolfe et al., 2010). Culturally tailored interventions have been developed to increase access to life-saving treatments for Indigenous people living with HIV, for example, collaborative approaches involving Indigenous communities' participation prioritizes relationship building, community readiness, trauma-informed care, and integration of traditional Indigenous healing practices (Jongbloed et al., 2019; Larcombe et al., 2019; Pearson et al., 2020; Worthington et al., 2020).

Despite improvements in HIV screening and testing, studies suggest that disparate HIV risk perception among marginalized peoples is associated with high rates of HIV risk behaviours (De Santis et al., 2017; Montaner et al., 2014; Negin et al., 2015). For Indigenous people WUID/A, high-risk behaviours often stem from the systemic impacts of colonization and discrimination (Barker et al., 2019; Milloy et al., 2016; Negin et al., 2015; Woodgate et al., 2017).

Interestingly, several participants' stories reveal that those engaged in high-risk behaviours were more likely to get tested in response. Moreover, participants' involvement with community-based research projects also contributed to an increase in HIV testing. Previous studies have discussed the role of research studies as being an important access point for healthcare (Sacristán et al., 2016). However, the reliance on research sites for testing in this instance does raise questions about the reach of conventional public health services that are designed to deliver HIV testing to marginalized populations. The reliance on research sites for testing may point to mistrust in healthcare systems that hinder access for many Indigenous people due to stigma and racism that stems from the enduring impacts of colonialism (Goodman et al., 2017).

While HIV-related stigma and discrimination is common among all people living with HIV, a higher level of HIV-related stigma and discrimination is typically experienced by Indigenous Peoples, due to a complex set of historical, political, and cultural factors (BC Office of the Provincial Health Officer, 2009; Reading et al., 2013; Woodgate et al., 2017). Some participants shared stories of facing stigma and discrimination within their own families and communities, much of which appeared to be rooted in a lack of knowledge about HIV transmission (e.g., you can't hug an HIV positive person). Research has shown that stigma and discrimination are often intensified in smaller communities - further preventing people from seeking HIV testing (Heckman et al., 1998; Orchard et al., 2010). Stigma is even more compounded for Indigenous women who experience gender discrimination, racism, and socioeconomic disadvantage (Ship \& Norton, 2000). Additionally, prior research has shown that those with internalized HIV stigma may have decreased confidence in their ability to adhere to HIV treatment regimens (Seghatol-Eslami et al., 2017).

Several participants shared stories of trauma related to the grief and loss of loved ones. Past work has also revealed how Indigenous Peoples have experienced overwhelming collective trauma as the result of ongoing systemic oppression and discrimination rooted in colonialism and colonial institutions (Allan \& 
Smylie, 2015; Loppie Reading \& Wien, 2013). Colonization and forced assimilation have fundamentally shifted and complicated how Indigenous Peoples experience the grieving process due to a history of multiple stressors, including, but not limited to, residential school experience (Spiwak et al., 2012). This intergenerational trauma has sometimes been referred to as a "soul wound" (Duran et al., 1998) with psychological symptoms (i.e., pain, suffering, and guilt) that are part of Survivor syndrome (Spiwak et al., 2012). Moreover, in many cases, HIV-related grief and bereavement can create significant mental health needs among people living with HIV, despite advancements in HIV treatment (Sikkeman et al., 2003).

Given that grief and loss related to HIV may serve to compound existing collective trauma resulting from colonialism, it is important that healthcare providers understand and recognize the value of trauma-based approaches in Indigenous models of care (Jongbloed et al., 2019; McCall \& LauridsenHoegh, 2014; Pearson et al., 2020). Our findings further emphasize the urgent need for HIV treatment and care programs to explicitly respond to the culturally specific needs of Indigenous people WUID/A by recognizing and attending to the complex relationship between trauma, grief, and systemic oppression (McCall \& Lauridsen-Hoegh, 2014; Pearson et al., 2019).

Our findings further suggest that current models of HIV screening, treatment, and care must expand efforts to develop or adapt interventions addressing intergenerational trauma and recognize the intricate relationship between trauma and systemic oppression. The importance of delivering community-based and culturally specific education and safe treatment is consistent with previous work that recognized the success of this strategy (Bingham et al., 2014; Canadian Aboriginal AIDS Network [CAAN], 2021; Flicker et al., 2015; Hillier et al., 2020; Jongbloed et al., 2019; Majumdar et al., 2004; Ontario HIV Treatment Network, 2019; Reading et al., 2013). Consistent with the recommendations from CAAN (2021), support for Indigenous people living with HIV demands meaningful and culturally relevant interventions. Culturally safe care and interventions should include more Indigenous healthcare staff, cultural opportunities in the form of traditional wellness practices, and the use of Elders to provide emotional support (Reading et al., 2013). Importantly, these interventions must be rooted in a culturally safe, trauma-informed, and patient-centred perspective (McCall \& Lauridsen-Hoegh, 2014). Notably, a research project that generated $29 \mathrm{HIV}$-related funding and policy recommendations directly from the lived experiences of Indigenous people living with HIV stressed the vital importance of improving access to culturally appropriate care and services (Hillier et al., 2020). Our findings further emphasize the needs for accessible harm reduction services and peer-led groups to explicitly respond to the culturally specific needs of Indigenous people WUID/A who are vulnerable to HIV.

Further, it is important to consider when exploring culturally safe HIV care, including HIV-related research, that conventional scientific HIV research approaches are often not consistent with Indigenous ways of knowing and epistemologies and, as such, do not sufficiently address the needs of Indigenous people living with HIV (Ryan et al., 2020). Indigenous epistemological and ontological considerations are necessary for culturally safe care and, thus, would allow Indigenous people living with HIV to exercise more self-determination, control, and autonomy of their own health services, including HIV prevention strategies (Flicker et al., 2019, Nowgesic, 2010; Ryan et al., 2020).

Throughout the talking circles, participants spoke about the significance of "reaching people on the street," namely, creating accessible and adequate HIV-related education for people experiencing 
homelessness. Research involving children experiencing homelessness reveals that peer education methods are a successful approach to increasing and improving knowledge and attitudes toward HIV (Khezri et al., 2019). As previously stated, as part of a tailored and multipronged approach for community-based and led interventions, strategies must be embedded and informed by the varied experiences of Indigenous people WUID/A.

Our study has some limitations. First, our research is limited to those experiences of a unique group of Indigenous people WUID/A associated with a community-led organization, and thus may not extend to all Indigenous Peoples. However, it is important to note that our findings may extend to other colonized settings (e.g., Australia and New Zealand), where Indigenous people experience similar health disparities (Negin et al., 2015; Shea et al., 2011). Further, our study does not capture the unique lived experiences of Indigenous women, queer, and two-spirit people living with HIV and, thus, warrants further investigation.

\section{Conclusion}

These findings illustrate an urgent need to address the social structural inequalities faced by Indigenous people WUID/A in relation to HIV that have arisen out of colonialism. The further development of culturally tailored strategies and programs that are directly informed by the diverse experiences of Indigenous people WUID/A hold promise for achieving effective HIV prevention, treatment, and care efforts. Despite efforts to increase HIV education, testing, and treatment, the health disparities and inequities faced by Indigenous people WUID/A have increased in recent years. Continued efforts by those in the healthcare sector must include a critical examination of the root causes of health and healthcare inequities among Indigenous people WUID/A within historical, socio-political, and cultural contexts.

\section{References}

Adelson, N. (2004). Reducing health disparities and promoting equity for vulnerable populations. Aboriginal Canada: Synthesis paper. In Reducing health disparities and promoting equity for vulnerable populations international think tank: Synthesis papers. Institute of Gender and Health.

Allan, B., \& Smylie, J. (2015). First Peoples, second class treatment: The role of racism in the health and well-being of Indigenous Peoples in Canada: Discussion paper. Wellesley Institute.

Barker, B., Adams, E., Wood, E., Kerr, T., DeBeck, K., Dong, H., Shoveller J., Montaner J., \& Milloy, M.J. (2019). Engagement in maximally-assisted therapy and adherence to antiretroviral therapy among a cohort of Indigenous People who use illicit drugs. AIDS and Behavior, 23(5), 12581266. https://doi.org/10.1007/s10461-018-2226-y

Bingham, B., Leo, D., Zhang, R., Montaner, J., \& Shannon, K. (2014). Generational sex work and HIV risk among Indigenous women in a street-based urban Canadian setting. Culture, Health \& Sexuality, 16(4), 440-452. https://doi.org/10.1080/13691058.2014.888480 
British Columbia Coroners Service. (2020). Illicit drug toxicity deaths in BC: January 1, 2010-March 31, 2020. https://www2.gov.bc.ca/assets/gov/birth-adoption-death-marriage-anddivorce/deaths/coroners-service/statistical/illicit-drug.pdf

British Columbia Office of the Provincial Health Officer. (2009). Pathways to health and healing: 2nd report on the health and well-being of Aboriginal people in British Columbia-Provincial Health Officer's annual report 2007. Ministry of Healthy Living and Sport. https://www2.gov.bc.ca/assets/gov/government/ministries-organizations/ministries/ health/office-of-indigenous-health/abohlth11-var7.pdf

Canadian Aboriginal AIDS Network. (2021). Home: CAAN. $\underline{\text { https://caan.ca/ }}$

Cardinal, N., \& Adin, E. (2005). An urban Aboriginal life: The 2005 indicators report on the quality of life of Aboriginal People in the Greater Vancouver region. Centre for Native Policy and Research. https://chodarr.org/sites/default/files/chodarr0247.pdf

Center for Disease Control and Prevention. (2017). HIV surveillance report. https://www.cdc.gov/hiv/pdf/library/reports/surveillance/cdc-hiv-surveillance-report-2017vol-29.pdf

City of Vancouver. (2013). Downtown Eastside local area profile. https://vancouver.ca/files/cov/profile-dtes-local-area-2013.pdf

City of Vancouver. (2017). City of Vancouver 2016 Census: Indigenous Peoples, immigration and ethno-cultural diversity. https://vancouver.ca/files/cov/2017-10-27-city-of-vancouver-2016census-indigenous-peoples-immigration-and-ethno-cultural-diversity.PDF

De Santis, J. P., Hauglum, S. D., Deleon, D. A., Provencio-Vasquez, E., \& Rodriguez, A. E. (2017). HIV risk perception, HIV knowledge, and sexual risk behaviors among transgender women in South Florida. Public Health Nursing, 34(3), 210-218. https://doi.org/10.1111/phn.12309

Duran, E., Duran, B., Heart, M. Y. H. B., \& Horse-Davis, S. Y. (1998). Healing the American Indian soul wound. In International handbook of multigenerational legacies of trauma (pp. 341-354). Springer. https://doi.org/10.1007/978-1-4757-5567-1_22

Fagan, P., \& McDonell, P. (2010). Knowledge, attitudes and behaviours in relation to safe sex, sexually transmitted infections (STI) and HIV/AIDS among remote living north Queensland youth. Australian and New Zealand Journal of Public Health, 34, S52-S56. https://doi.org/10.1111/j.1753-6405.2010.00554.x

Flicker, S., O’Campo, P., Monchalin, R., Thistle, J., Worthington, C., Masching, R., Guta, A., Pooyak, S., Whitebird, W., \& Thomas, C. (2015). Research done in "a good way": The importance of Indigenous Elder involvement in HIV community-based research. American Journal of Public Health, 105(6), 1149-1154. https://doi.org/10.2105/AJPH.2014.302522 
Flicker, S., Native Youth Sexual Health Network, Wilson, C., Monchalin, R., Oliver, V., Prentice, T., Jackson, R., Larkin, J., Mitchell, C., \& Restoule, J. P. (2019). "Stay strong, stay sexy, stay Native”: Storying Indigenous youth HIV prevention activism. Action Research, 17(3), 323-343. https://doi.org/10.1177/1476750317721302

Goldenberg, S. M., Deering, K., Amram, O., Guillemi, S., Nguyen, P., Montaner, J., \& Shannon, K. (2017). Community mapping of sex work criminalization and violence: Impacts on HIV treatment interruptions among marginalized women living with HIV in Vancouver, Canada. International Journal of STD \& AIDS, 28(10), 1001-1009. https://doi.org/10.1177/0956462416685683

Goodman, A., Fleming, K., Markwick, N., Morrison, T., Lagimodiere, L., Kerr, T., \& Western Aboriginal Harm Reduction Society. (2017). "They treated me like crap and I know it was because I was Native": The healthcare experiences of Aboriginal Peoples living in Vancouver's inner city. Social Science \& Medicine, 178, 87-94. https://doi.org/10.1016/j.socscimed.2017.01.053

Goodman, A., Morgan, R., Kuehlke, R., Kastor, S., Fleming, K., \& Boyd, J. (2018). “We've been researched to death": Exploring the research experiences of urban Indigenous Peoples in Vancouver, Canada. International Indigenous Policy Journal, 9(2). https://doi.org/10.18584/iipj.2018.9.2.3

Goodyear, M. D., \& Cusick, L. (2007). Protection of sex workers. BMJ, 334, 52. https://doi.org/10.1136/bmj.39087.642801.BE

Hatzenbuehler, M. L., O’Cleirigh, C., Mayer, K. H., Mimiaga, M. J., \& Safren, S. A. (2011). Prospective associations between HIV-related stigma, transmission risk behaviors, and adverse mental health outcomes in men who have sex with men. Annals of Behavioral Medicine, 42(2), 227-234. https://doi.org/10.1007/s12160-011-9275-z

Heckman, T. G., Somlai, A., Peters, J., Walker, J., Otto-Salaj, L., Galdabini, C., \& Kelly, J. (1998). Barriers to care among persons living with HIV/AIDS in urban and rural areas. AIDS Care, 10(3), 365-375. https://doi.org/10.1080/713612410

Hillier, S. A., Winkler, E., \& Lavallée, L. (2020). Decolonising the HIV care cascade: Policy and funding recommendations from Indigenous Peoples living with HIV and AIDS. International Journal of Indigenous Health, 15(1), 48-60. https://doi.org/10.32799/ijih.v15i1.34001

HIV/AIDS and Indigenous Peoples. (2009). Final report of the 5th International Policy Dialogue. https://www.deslibris.ca/IDFR/227930

Hyshka, E., Strathdee, S., Wood, E., \& Kerr, T. (2012). Needle exchange and the HIV epidemic in Vancouver: Lessons learned from 15 years of research. International Journal of Drug Policy, 23(4), 261-270. https://doi.org/10.1016/j.drugpo.2012.03.006

Jackson, R., \& Reimer, G. (2008). Canadian Aboriginal People living with HIV/AIDS: Care, treatment and support issues: Canadian Aboriginal AIDS Network. 
Jongbloed, K., Pooyak, S., Sharma, R., Mackie, J., Pearce, M. E., Laliberte, N., Demerais L., Lester R. T., Schechter M. T., Loppie, C., Spittal P. M., \& Cedar Project Partnership. (2019). Experiences of the HIV cascade of care among Indigenous Peoples: A systematic review. AIDS and Behavior, 23(4), 984-1003. https://doi.org/10.1007/s10461-018-2372-2

Kazempiur, A., \& Halli, S. S. (2000). Neighbourhood poverty in Canadian cities. Canadian Journal of Sociology/Cahiers canadiens de sociologie, 369-381. https://doi.org/10.2307/3341647

Khezri, M., Farokhzadian, J., Nematollahi, M., Foroughameri, G., \& Sharifi, H. (2019). HIV/AIDS prevention education: An effective tool for enhancing street children's knowledge and attitude. A randomized controlled trial. Children and Youth Services Review, 104, 104351. https://doi.org/10.1016/j.childyouth.2019.05.028

Larcombe, L., McLeod, A., Samuel, S., Samuel, J., Payne, M., Van Haute, S., Singer M., Ringaert, L., Meyers, A. F. A., Kinew, K., Keynan, Y., MacDonald, K., Antsanen, J., \& Orr, P. (2019). A Dene First Nation's community readiness assessment to take action against HIV/AIDS: A pilot project. International Journal of Circumpolar Health, 78(1), 1588092. https://doi.org/10.1080/22423982.2019.1588092

Lavallée, L. F. (2009). Practical application of an Indigenous research framework and two qualitative Indigenous research methods: Sharing circles and Anishnaabe symbol-based reflection. International Journal of Qualitative Methods, 8(1), 21-40. https://doi.org/10.1177/160940690900800103

Liamputtong, P. (2013). Stigma, discrimination and living with HIV/AIDS: A cross-cultural perspective: Springer Science \& Business Media. https://doi.org/10.1007/978-94-007-6324-1

Loppie Reading, C., \& Wien, F. (2013). Health inequalities and the social determinants of Aboriginal Peoples' health. National Collaborating Centre for Aboriginal Health.

Majumdar, B. B., Chambers, T. L., \& Roberts, J. (2004). Community-based, culturally sensitive HIV/AIDS education for Aboriginal adolescents: Implications for nursing practice. Journal of Transcultural Nursing, 15(1), 69-73. https://doi.org/10.1177/1043659603260015

Martin, L. J., Houston, S., Yasui, Y., Wild, T. C., \& Saunders, L. D. (2011). All-cause and HIV-related mortality rates among HIV-infected patients after initiating highly active antiretroviral therapy: The impact of Aboriginal ethnicity and injection drug use. Canadian Journal of Public Health, 102(2), 90-96. https://doi.org/10.1007/BF03404154

McCall, J., \& Lauridsen-Hoegh, P. (2014). Trauma and cultural safety: Providing quality care to HIVinfected women of Aboriginal descent. Journal of the Association of Nurses in AIDS Care, 25(1), S70-S78. https://doi.org/10.1016/j.jana.2013.05.005

Miller, C. L., Johnston, C., Spittal, P. M., Li, K., LaLiberté, N., Montaner, J. S., \& Schechter, M. T. (2002). Opportunities for prevention: Hepatitis $C$ prevalence and incidence in a cohort of 
young injection drug users. Hepatology, 36(3), 737-742. https://doi.org/10.1053/ jhep.2002.35065

Milloy, M. J., King, A., Kerr, T., Adams, E., Samji, H., Guillemi, S., Wood, E., \& Montaner, J. (2016). Improvements in HIV treatment outcomes among Indigenous and non-indigenous people who use illicit drugs in a Canadian setting. Journal of the International AIDS Society, 19(1), 20617. https://doi.org/10.7448/IAS.19.1.20617

Mitchell, C. M., Kaufman, C. E., \& Beals, J. (2004). Identifying diverse HIV risk groups among American Indian young adults: The utility of cluster analysis. AIDS and Behavior, 8(3), 263275. https://doi.org/10.1023/B:AIBE.0000044074.46636.c2

Montaner, J. S., Lima, V. D., Harrigan, P. R., Lourenço, L., Yip, B., Nosyk, B., Wood E., Kerr T., Shannon K., Moore, D., Hogg, R. S., Barrios, R., Gilbert, M., Krajden, M., Gustafson, R., Daly, P., \& Kendall, P. (2014). Expansion of HAART coverage is associated with sustained decreases in HIV/AIDS morbidity, mortality and HIV transmission: The "HIV treatment as prevention" experience in a Canadian setting. PloS ONE, $9(2)$. https://doi.org/10.1371/journal.pone.0087872

Negin, J., Aspin, C., Gadsden, T., \& Reading, C. (2015). HIV among Indigenous Peoples: A review of the literature on HIV-related behaviour since the beginning of the epidemic. AIDS and Behavior, 19(9), 1720-1734. https://doi.org/10.1007/s10461-015-1023-0

Nowgesic, E. (2010). Addressing HIV/AIDS among Aboriginal People using a health status, health determinants and health care framework: A literature review and conceptual analysis. Canadian Journal of Aboriginal Community-Based HIV/AIDS Research, 3(35).

O’Brien, N., Martin, C., Peltier, D., Kaida, A., Becker, M., Bourassa, C., Gervais, L., Bruce, S., Loutfy, M., \& de Pokomandy, A. (2020). Employing Indigenous methodologies to understand women's perceptions of HIV, health, and well-being in Quebec, Canada. International Review of Qualitative Research, 13(2), 160-181 https://doi.org/10.1177/1940844720934366

Ontario HIV Treatment Network. (2019). Unmet needs of Indigenous Peoples living with HIV. http://www.ohtn.on.ca/rapid-response-unmet-needs-of-indigenous-peoples-living-with-hiv/

Orchard, T. R., Druyts, E., McInnes, C. W., Clement, K., Ding, E., Fernandes, K. A., Anema A., Lima V. D., \& Hogg, R. S. (2010). Factors behind HIV testing practices among Canadian Aboriginal Peoples living off-reserve. AIDS Care, 22(3), 324-331. https://doi.org/10.1080/ $\underline{09540120903111510}$

Pearson, C. R., Kaysen, D., Huh, D., \& Bedard-Gilligan, M. (2019). Randomized control trial of culturally adapted cognitive processing therapy for PTSD substance misuse and HIV sexual risk behavior for Native American women. AIDS and Behavior, 23(3), 695-706. https://doi.org/ $\underline{10.1007 / s 10461-018-02382-8}$ 
Pearson, C. R., Kaysen, D., Huh, D., Bedard-Gillgan, M., Walker, D., Marin, R., \& Saluskin, K. (2020). A randomized comparison trial of culturally adapted HIV prevention approaches for Native Americans reducing trauma symptoms versus substance misuse: The Healing Seasons protocol. Contemporary Clinical Trials, 95, 106070. https://doi.org/10.1016/j.cct.2020.106070

Price, J. T., Rosenberg, N. E., Vansia, D., Phanga, T., Bhushan, N. L., Maseko, B., Brar, S. K., Hosseinipour, M. C., Tang, J. H., Bekker, L. G., \& Pettifor, A. (2018). Predictors of HIV, HIV risk perception, and HIV worry among adolescent girls and young women in Lilongwe, Malawi. Journal of Acquired Immune Deficiency Syndromes, 77(1), 53-63. https://doi.org/10.1097/ QAI.0000000000001567

Public Health Agency of Canada. (2018). Summary: Estimates of HIV incidence, prevalence and Canada's progression on meeting the 90-90-90 HIV targets, 2016. http://www.canada.ca/content/dam/phac-aspc/documents/services/publications/ diseases-conditions/summary-estimates-hiv-incidence-prevalence-canadasprogress-90-90-90/pub-eng.pdf

Reading, C., Brennan, R., \& Masching, R. (2013). Cultural concepts of care among Aboriginal People living with HIV and AIDS: A study by the Canadian Aboriginal AIDS Network. Canadian Journal of Aboriginal Community-Based HIV/AIDS Research, 5, 24-28. https://www.ahacentre.ca/uploads/9/6/4/2/96422574/cultural_concepts_of_care.pdf

Ryan, C., Jackson, R., Gabel, C., King, A., Masching, R., \& Thomas, E. C. (2020). Successful aging: Indigenous men aging in a good way with HIV/AIDS. Canadian Journal on Aging/La Revue canadienne du vieillissement, 39(2), 305-317. https://doi.org/10.1017/S0714980819000497

Sacristán, J. A., Aguarón, A., Avendaño-Solá, C., Garrido, P., Carrión, J., Gutiérrez, A., Kroes, R., \& Flores, A. (2016). Patient involvement in clinical research: Why, when, and how. Patient Preference and Adherence, 10, 631-640. https://doi.org/10.2147/PPA.S104259

Seghatol-Eslami, V. C., Dark, H., Raper, J. L., Mugavero, M. J., Turan, J. M., \& Turan, B. (2017). Interpersonal and intrapersonal factors as parallel independent mediators in the association between internalized HIV stigma and ART adherence. Journal of Acquired Immune Deficiency Syndromes, 74(1). https://doi.org/10.1097/QAI.0000000000001177

Shannon, K., Kerr, T., Allinott, S., Chettiar, J., Shoveller, J., \& Tyndall, M. W. (2008). Social and structural violence and power relations in mitigating HIV risk of drug-using women in survival sex work. Social Science \& Medicine, 66(4), 911-921. https://doi.org/10.1016/ j.socscimed.2007.11.008

Shea, B., Aspin, C., Ward, J., Archibald, C., Dickson, N., McDonald, A., Penehira, M., Halverson, J., Masching, R., McAllister, S., Smith L. T., Kaldor J. M., \& Andersson, N., \& McAllister, S. (2011). HIV diagnoses in Indigenous Peoples: Comparison of Australia, Canada and New Zealand. International Health, 3(3), 193-198. https://doi.org/10.1016/j.inhe.2011.03.010 
Ship, S., \& Norton, L. (2000). "It's hard to be a women [sic]": First Nations women living with HIV/AIDS. Native Social Work Journal, 3(1), 73-89.

Sikkema, K. J., Kochman, A., DiFranceisco, W., Kelly, J. A., \& Hoffmann, R. G. (2003). AIDS-related grief and coping with loss among HIV-positive men and women. Journal of Behavioral Medicine, 26(2), 165-181. https://doi.org/10.1023/A:1023086723137

Smith, L. T. (2013). Decolonizing methodologies: Research and Indigenous Peoples. Zed Books Ltd.

Spittal, P. M., Craib, K. J., Wood, E., Laliberté, N., Li, K., Tyndall, M. W., O’Shaughnessy, M., \& Schechter, M. (2002). Risk factors for elevated HIV incidence rates among female injection drug users in Vancouver. CMAJ, 166(7), 894-899.

Spiwak, R., Sareen, J., Elias, B., Martens, P., Munro, G., \& Bolton, J. (2012). Complicated grief in Aboriginal populations. Dialogues in Clinical Neuroscience, 14(2), 204-209. https://doi.org/10.31887/DCNS.2012.14.2/rspiwak

Statistics Canada. (2015). Table 3: Distribution of First Nations people, First Nations people with and without Registered Indian Status, and First Nations people with Registered Indian Status living on or off reserve, Canada, provinces and territories, 2011. www12.statcan.gc.ca/nhs$\underline{\mathrm{enm} / 2011 / \mathrm{as}-\mathrm{sa} / 99-011-\mathrm{x} / 2011001 / \mathrm{tbl} / \mathrm{tbl03} \text {-eng.cfm }}$

Statistics Canada. (2018). First Nations people, Métis and Inuit in Canada: Diverse and growing populations. https://www150.statcan.gc.ca/n1/pub/89-659-x/89-659-x2018001-eng.htm

Tuck, E. (2009). Re-visioning action: Participatory action research and Indigenous theories of change. The Urban Review, 41(1), 47-65. https://doi.org/10.1007/s11256-008-0094-x

Werb, D., Debeck, K., Kerr, T., Li, K., Montaner, J., \& Wood, E. (2010). Modelling crack cocaine use trends over 10 years in a Canadian setting. Drug and Alcohol Review, 29(3), 271-277. https://doi.org/10.1111/j.1465-3362.2009.00145.x

Wolfe, D., Carrieri, M. P., \& Shepard, D. (2010). Treatment and care for injecting drug users with HIV infection: A review of barriers and ways forward. The Lancet, 376(9738), 355-366. https://doi.org/10.1016/S0140-6736(10)60832-X

Wood, E., \& Kerr, T. (2006). What do you do when you hit rock bottom? Responding to drugs in the City of Vancouver. International Journal of Drug Policy, 2(17), 55-60. https://doi.org/ 10.1016/j.drugpo.2005.12.007

Woodgate, R. L., Zurba, M., Tennent, P., Cochrane, C., Payne, M., \& Mignone, J. (2017). "People try and label me as someone I'm not": The social ecology of Indigenous people living with HIV, stigma, and discrimination in Manitoba, Canada. Social Science \& Medicine, 194, 17-24. https://doi.org/10.1016/j.socscimed.2017.10.002

Worthington, C., Mollison, A., Herman, T., Johnston, C., Masching, R., Pooyak, S., Lee, R., \& Loutfy, M. (2020). A qualitative study of community-based HIV/AIDS prevention interventions, 
programs, and projects for rural and remote regions in Canada: Implementation challenges and lessons learned. Journal of Public Health Management and Practice, 26(1), E28-E37.

https://doi.org/10.1097/PHH.0000000000000878 